\title{
Atualidades/Actualities
}

\section{DOMICILIAÇÃO DE TRIATOMINEOS OU PRÉ-ADAPTAÇÃO A ANTROPOFILIA E À ORNITOFILIA?}

Mario B. Aragão*

\begin{abstract}
ARAGãO, M.B. Domiciliação de triatomíneos ou pré-adaptação à antropofilia e à ornitofilia? Rev. Saúde públ., S. Paulo, 17:51-5, 1983.

RESUMO: Nas áreas onde se considera que os triatomíneos não se adaptaram aos domicílios, tem sido encontradas colônias, desses insetos, em casas habitadas por mamíferos silvestres ou sinantrópicos. As determinações de sangue feitas em triatomíneos, coletados nos domicílios ou seus anexos, apresentam concordância com os dados obtidos em exemplares capturados em biótopos naturais, desde que esses dados sejam reunidos em dois grupos: mamíferos e aves. Essas informações relativas às preferências alimentares das espécies de triatomineos mais bem estudadas e a constatação de pré-adaptação à mudança de condições de ambiente ou de fonte de alimento, em vários grupos de seres vivos, conduziram às seguintes conclusões: 1 Havendo condições para abrigo dos insetos, o desenvolvimento de colônias de triatomíneos, nos comicílios, independe de suas características. $2-0$ elemento fundamental para a colonização de um biótopo artificial, por triatomíneos, é o vertebrado que habita esse biótopo. 3 - O fato de umas espécies ocorrerem em ciomicílios e outras em abrigos de aves, é decorrência de pré-adaptação. Na natureza a espécie é polífaga e tem preferência pela classe de vertebrado que habita o biótopo. 4 - A conclusão anterior permite alguma previsão sobre o que poderia ocorrer em regiões de colonização recente, como a Amazônica.
\end{abstract}

UNITERMOS: Triatomíneos, domiciliação. Triatomíneos, pré-adaptaçâo.

\section{INTRODUÇAO}

Em artigo anterior (Aragão ${ }^{1}, 1982$ ) mostrou-se que as espécies de triatomíneos, ditas domiciliadas, apresentam, em condições naturais, duas caracteristicas em comum: alimentação eclética e preferência por sangue de mamífero. Por outro lado, as espécies mais freqüentes no peridomicilio têm sido encontradas, nos biótopos naturais, com, pelo menos, $40 \%$ dos exemplares contendo sangue de ave. Esses fatos podem ser facilmente observados nos gráficos apresentados por Minter ${ }^{13}$ (1975). Para quatro espécies, esses gráficos estão baseados em algumas centenas de determinações de sangue: Rhodnius prolixus e Panstrongylus megistus, com percentagens de sangue de mamifero da ordem de $80 \%$, Triatoma sordida com $60 \%$ e Rhodnius neglectus com

\footnotetext{
* Da Escola Nacional de Saúde Pública - Rua neopoldo Bulhōes, 1480 - 21041 - Rio de Janeiro RJ - Brasil.
} 
ARAGAO, M.B. Domiciliação de triatomíneos ou pré-adaptação à antrofilia e à ornitofilia? Rev. Saúde públ., S. Paulo, 17:51-5, 1983

valores em torno de $40 \%$. Salvo o caso do $R$. prolixus, com $9 \%$ dos exemplares contendo sangue de largato, os restantes repastos foram feitos em aves.

E fato geralmente aceito que não existe doença de Chagas nos Estados Unidos, porque as casas são de boa qualidade. 0 mesmo podendo ser repetido em relação ao Planalto de Curitiba, no Paraná, onde as condições de vida não são das piores. Acontece que, em ambas as áreas, têm sido encontrados domicílios com triatomineos. Yaeger 2: (1959) menciona uma colônia de Triatoma lectularius em ninho de rato, dentro de uma casa no Texas. Tarshis ${ }^{19}$ (1963) cita o encontro de diversos adultos e ninfas de Triatoma protracta em uma casa de dois andares no município de Los Angeles e diz ser comum o encontro desses triatomíneos em pilhas de madeira e outros materiais de construção. O que também foi observado por Forattini e col.6,7 (1977, 1978) con P. megistus, no Estado de São Paulo. Williams e col.21 (1977) encontraram, no Texas, um canil infestado pelo $T$. protracta oculta. Luz 12 (1976) menciona o encontro de colônias de $P$. megistus em casas abandonadas ou usadas em fins de semana, no Planalto de Curitiba, e onde havia ninhos de gambás ou de ratos, fato também observado em São Paulo (Rocha e Silva e col.17, 1975).

Essas observações feitas nos Estados Unidos, no Paraná e em São Paulo, parecem indicar que o fato dos triatomíneos colonizarem $\mathrm{cm}$ biótopos artificiais não se prende ao domicilio em si e sim aos serss habitantes. Amontoados de material de construção ou casas têm sido colonizados desde que neles existam os animais preferidos pelos triatomíneos.

\section{Os Triatominios nos Biotopos Artificiais}

O R. prolixus é o grande transmissor da doença de Chagas na Venezuela e os dados disponiveis (Pifano ${ }^{14}$, , 1973) referem-se a repastos feitos, nos domicílios, apenas no homem e outros mamiferos. Sem conhecer a área é difícil saber se trata-se de preferência do inseto ou ausência de aves nas casas.

O $P$. megistus é mais eclético na alimentação. No domicílio e no peridomicílio, suga 0 homem, quase todos os animais domésticos e alguns silvestres. Além disso, forma colônias estáveis em galinheiros experimentais (Forattini e col.e, 1977).

o $T$. sordida, nos biótopos artificiais, é tão eclético quanto o $P$. megistus, porém, com maior preferência por ave (Minter 12, 1975). Em diversas ocasiões tem sido encontrado formando grandes colônias a custa de pardais ou andorinhas, em forros e beirais de casas de boa construção (Freitas e col. ${ }^{11}$, 1960; Forattini e col. ${ }^{4}$ 1971). Em geral, as coletas feitas nos anexos fornecem número muito mais elevado de exemplares do que as das casas (Forattini e col..3 1971) e forma colônias estáveis en galinheiros experimentais (Forattini e col. ${ }^{5}, 1973$ ). Num ensaio experimental, Rocha e Silva e col.1s (1977) verificaram que as ninfas de $1^{\text {" }}$ estádio preferem sugar pombo, tendo à disposição também um antebraço humano.

O $R$. neglectus, em biótopos artificiais, praticamente, só tem sido encontrado em anexos e, assim mesmo, em colônias pouco numerosas (Forattini e col.4, 1971). Em galinheiros experimentais tem desenvolvido colônias de meia centena de exemplares (Forattini e col.4,8, 1971, 1979).

Com respeito ao Triatoma arthurneivai que, devido a viver entre pedras, deve estar ligado a lagartos, há uma observação muito interessante de Forattini e col. ${ }^{5}$ (1973). Essa espécie formou uma colônia, num galinheiro experimental, que se extinguiu espontaneamente.

\section{DISCUSSÃO}

A pré-adaptação é um fenômeno comum na natureza e dele tem sido tirado proveito, principalmente, no controle biológico de pragas da agricultura (Debach 2, 1974; National Academy of Sciences $\left.{ }^{14}, 1978\right)$. Este manual ${ }^{14}$, discutindo os fatores genéticos que devem ser levados em conta na intro- 
dução de um organismo insetívoro, diz que ele deve estar pré-adaptado, em certo grau, ao novo ambiente e que essa adaptação pode se ampliar depois da colonização. Em apoio à primeira afirmativa observa que em $80 \%$ dos casos de controle biológico efetivo, esse êxito foi obtido nas três primeiras gerações depois da colonização. Outro fato comum a esses insetivoros introduzidos, em novas áreas, é o deles se alimentarem, na região de origem, de espécies afins a que eles passam a controlar. O mesmo acontecendo com insetos fitófagos que, as vezes, tornam-se pragas de plantas recém introduzidas. Sobre o assunto, Peters ${ }^{15}$ (1977), referindo-se a plantas mostra-se categórico: "para ter sucesso, numa invasão, o propágulo deve atingir um local onde exista um nicho desocupado, para o qual ele esteja pri-adaptado".

Em um dos seus estudos sobre lagartos brasileiros, Vanzolini e Williams 20 (1981) declaram que, devido à rapidez das mudanças climáticas do periodo Quaternário, a probabilidade das formas da floresta se adaptarem à semi aridez deve ter sido muito baixa. Acrescentam, entretanto, que essa probabilidade aumentaria muito se a população estivesse, de alguma forma, préadaptada, isto é, fosse tolerante ou talvez preferisse as margens ou outras situaçōes entre as duas ecologias extremas, mencionando em seguida alguns exemplos. Uma espécie, Gonatodes humeralis, em 37 localidades foi encontrada na parte baixa do tronco das árvores da floresta, em 4 localidades estava na periferia de mata secundária e, numa outra, em área de vegetaçāo aberta. Outra, Plica plica, em uma localidade foi coletada em mangueiras isoladas e, em dezenas de outras, em plena floresta. Citam, também, o caso do gênero Mabuya que tem espécies de áreas abertas e de floresta, porém, essas últimas são sempre heliófilas, habitando clareiras ou situações marginais.

Entre os triatomíneos, o $P$. megistus apresenta bastante semelhançá com os lagartos, acima mencionados. No sul da Serra do Mar de São Paulo parece mais restrito à alimentação em mamíferos silves- tres, uma vez que Forattini e col.7 (1978) não conseguiram a colonização de galinheiros experimentais, em área onde cs adultos costumam voar para dentro das casas. Ainda no Estado de São Paulo, na mesma latitude, e máis para o sul, em Curitiba, a espécie apesar de não proliferar nos domicílios, coloniza em galinheiros (Luz I2, 1976; Forattini e col. ${ }^{7}$, 1978). Já no norte de São Paulo a espécie é francamente polifaga, porém, com baixa antropofilia e da Bahia para o norte é altamente antropófila (Minter ${ }^{13}$, 1975; Forattini e col.9 1981).

Recentemente Forattini ec col.10 (1982) Eucontraram uma exúvia ninfal de quarto estádio de $P$. megistus numa casa situada na Serra do Mar de São Paulo, onde o morador havia coletado adultos e nove ninfas de primeiro estádio. Fato esse que se assemelha à colonização do galinheiro experimental pelo $T$. arthurneivai, antes mencionada.

Para as outras espécies os dados são escassos, não podendo acrescentar maiores contribuiçōes.

\section{CONCLUSOES}

Os fatos apresentados parecem permitir as seguintes conclusōes:

1. Havendo condiçōes para abrigo dos insetos, o desenvolvimento de colônias de triatomineos em domicilios independe das características da construção. Como exemplos extremos tem-se os beirais de casas de alvenaria e as cafuas de pau-a-pique.

2. O elemento fundamental para a colonização de um biótopo artificial, por triatomineos, é o vertebrado que habita esse biótopo. Como exemplo tem-se os montes de tijolos e de táboas, onde têm sido encontradas colônias desses insetos.

3. O fato de umas espécies ocorrcirin em domicílios e outras em abrigos de aves, é decorrência de pré-adaptaçắc. 
ARAGAO, M.B. Domiciliação de triatomíneos ou pré-adaptação a antrofilia e à ornitofilia? Rev. Saúde públ., S. Paulo, 17:51-5, 1983

$\mathrm{Na}$ naureza, a espécie é polifaga e tem preferência pela classe de vertebrado que habita o biótopo artificial. Como exemplo têm-se uma verdadeira gradação: $P$. megistus, casas e anexos; $T$. sordida, anexos, principalmente, habitados por aves e casas; $R$. neglectus, anexos habitados por aves.
4. A conclusão anterior permite que se faça previsão do que poderá acontecer com as espécies da Amazônia, quando essa região tornar-se francamente povoada. Sendo assim, torna-se de grande interesse $o$ estudo das preferências alimentares dessas espécies, nos seus biótopos naturais.

ARAGAO, M.B. [Domiciliary adaptation of triatomine or pre-adaptation to anthropophily and ornithophily?] Rev. Saúde públ., S. Paulo, 17:51-5, 1983.

ABSTRACT: In the areas where triatomine bugs have not adapted to human habitations, colonies of these insects have been found in houses occupied by sylvatic or sinanthropic mammals. Bloodmeal identifications from triatomine collected in human habitations and their surroundings usually correlate with those from specimens collected in natural biotopes, when two groups of data are considered, those from birds and mammals. This information related to the food preferences of the more fully studied triatomine and the occurrence of the pre-adaptation to changes in environmental und feeding conditions, well known in many animal groups, led to the following conclusions: 1 - The colonization of human habitations by triatomine is, generally independent of the type of habitation. 2 - The fundamental determining factor for the colonization of an artificial biotope by triatomine is the vertebrate class that lives in it. 3 - Some species occur in human habitations and others in bird nests as a consequence of pre-adaptation. The insect species is a multi-feeder in its natural environment and has a preference for the class of vertebrate inhabiting the biotope. 4 - The above mentioned conclusion indicates that predictions in regard to future colonization of human habitations can be made and this is specially important for the Amazon Region.

UNITERMS: Triatomine, domiciliation. Triatominae, preadaptation.

\section{REFERENCIAS BIBLIOGRAFICAS}

1. ARAGAO, M.B. Sobre a domiciliação dos triatomineos. Rev. Soc. bras. Med. trop., 1982. [no prelo]

2. DEBACH, P. Biological control by natural enemies. Cambridge, Cambridge Universyty Press, 1974.

3. FORATTINI, O.P. et al. Aspectos ecológicos da tripanossomose americana. II Distribuição e dispersão local de triatomineos em ecótopos naturais e artificlais. Rev. Saúde públ., S. Paulo, 5:163-91,1971.

4. FORATTINI, O.P. et al. Aspectos ecológicos da tripanossomose americana. III Dispersão local de triatomineos, com especial referência ao Triatoma sordida. Rev. Saúde públ., S. Paulo, 5:193-205,1971.
5. FORATTINI, O.P. et al. Aspectos ecológicos da tripanossomose americana. $\mathrm{V}$ Observações sobre colonização espontanea de triatomíneos silvestres em ecótopos artificiais, com especial referência ao Triatoma sordida. Rev. Saúde públ., S. Paulo, 7:219-39, 1973.

6. FORATTINI, O.P. et al. Aspectos ecológicos da tripanossomíase americana. VIII Domiciliaçăo de Panstrongylus megistus e sua presença extradomiciliar. Rev. Saúde públ., S. Paulo, 11:73-86, 1977. 
ARAGÁ, M.B. Domiciliaçăo de triatomíneos ou pré-adaptaçăo à antrofilia e à ornitofilia? Rev. Saude puibl., S. Paulo, 17:51-5, 1983

7. FORATTINI, O.P. et al. Aspectos ecologicos da tripanossomiase americana. XII Variação regional da tendência de Panstrongylus megistus à domiciliação. Rev. Saíde públ., S. Paulo, 12:209-33, 1978.

8. FORATTINI, O.P. et al. Aspectos ecológicos da tripanossomiase americana. XIV Persistência e potencial de domiciliação de populações triatominicas silvestres em região de intensa atividade agropecuária. Rev. Saúde públ., S. Paulo, $13: 123-46$, 1979 .

9. FORATTINI, O.P. et al. Hábitos alimentares, infecção natural e distribuição de triatomíneos domiciliados na região nordeste do Brasil. Rev. Saúde públ., S. Paulo, $15: 113-64,1981$.

10. FORATTINI, O.P. et al. Nota sobre a domiclliaçăo de Panstrongylus megistus no litoral sul do Estado de São Paulo, Brasil. Rev. Saúde públ., S. Paulo, $16: 127-31,1982$.

11. FREITAS, J.L.P. et al. Investigaçס̃es epidemiológicas sobre triatomíneos de hábitos domésticos e silvestres com auxílio da reação de precipitina. Rev. Inst. Med. trop. S. Paulo, 2:90-9, 1960.

12. LUZ, E. Focos silvestres do Trypanosoma cruzi no litoral e primeiro planalto paranaense. An. Med. Univ. F'ed. Parana, 19:7-51, 1976.

13. MINTER, D. M. Feeding patterns of some triatomine vector species. In: International Symposium on New Approaches in American Trypanosomiasis Research, Belo Horizonte, 1975. Proceedings. Washington, D.C., Pan-American Health Organization, 1976. p. 33-46. (PAFO Scient. Públ., 318).

14. NATIONAL ACADEMY OF SCIENCES. Manejo y control de plagas de insectos. México, Editorial Limusa, 1978.
15. PETERS, T.M. The biology of invasions, In: Kuiman, H.M. \& Chiang, H.C. ed. Insect ecology; Papers presented in the A.C. Hodson Lectures, 1977. p. 56-72. (Expt. Sta. Tech. Bul. 310). [separata]

16. PIFANO, F. La dinamica epidemiológica de la enfermedade de Chagas en el valle de los Naranjos, Estado Carabobo, Venezuela. II - La infección chagasica en la población rural del área. Arch. venez. Med. trop. Parasit. med., 5:31-45,1973.

17. ROCHA E SILVA, E.O. et al. Importancia dos animals sinantróplcos no controle da endemia chagásica. Rev. Saúde públ., S. Paulo, 9:371-81, 1975.

18. ROCHA E SILVA, E.O. et al. Preferência alimentar (entre sangue himano e ave) dos Triatoma sordida encontrados em casas habitadas da região norte do Estado de São Paulo, Brasil. Rev. Saúde puibl., S. Paulo, 11:258-69, 1977.

19. TARSHIS, I.B. Preliminary laboratory and field studies on the utilization of Dri-Die 67 and two percent Dibrom-Dri-Die 67 for the control of the western cone-nosed bug, Triatoma protracta (Uhler). Amer. J. trop. Med. Hyg., $12: 96-102,1963$.

20. VANZOLINI, P.E. \& WIILIAMS, E.E. The vanishing refuge: a mechanism for ecogeographic speciation. Pap. avuls. Zool., S. Paulo, 34:251-5, 1981.

21. WILLIAMS, G.D. et al. Naturally occurring trypanosomiasis (Chagas' disease) in dogs. J. Amer. vet. med. Ass., 171:171-7, 1977.

22. YAEGER, R. G. Chagas' disease in the United States. Rev. goiana med., 5:461-70, 1959.

Recebiāo para publicasāo em $25 / 10 / 1982$

Aprovado para publicação em 17/12/1982 